\title{
Trajetórias da sobrevivência da arquitetura e do patrimônio cultural quilombola: memórias e interferências
}

\author{
Trajectories of the survival of quilombola architecture and cultural \\ heritage: memories and interferences
Trayectorias de supervivencia de la arquitectura quilombola y el patrimonio cultural: memorias e interferencias

\author{
Luis Otavio Cunha Prado ${ }^{1}$ \\ Dayane Máximo \\ Leonardo de Oliveira Carneiro ${ }^{3}$
}

\begin{abstract}
Resumo
A memória e a história são os componentes que difundem a identidade ao indivíduo, mas são regradas por interferências e transformações. Nesse sentido, este artigo tem como principal objetivo analisar de forma crítica de que modo a arquitetura e o patrimônio cultural quilombola tem sobrevivido. Desse modo, metodologicamente, foi feito uma análise, fazendo o uso do materialismo histórico dialético, a partir das seguintes categorias: história, contradição e trabalho. Com isso, foi obtido como resultado que as diversas formas de construir foram modificadas; tanto o método de trabalho como suas configurações arquitetônicas. Além disso, foi alcançado que parte da memória sofreu modificações, implicadas pela burguesia, o capital e o estado, mas se mantém em partes dada a oralidade e a dimensão territorial.
\end{abstract}

Palavras-Chave: arquitetura quilombola; patrimônio cultural; memória quilombola; afro-brasileiro.

\section{Resumen}

La memoria y la historia son los componentes que transmiten la identidad al individuo, pero se rigen por interferencias y transformaciones. En este sentido, el objetivo principal de este artículo es analizar críticamente cómo ha sobrevivido la arquitectura y el patrimonio cultural quilombolas. Así, metodológicamente, se realizó un análisis, utilizando el materialismo histórico dialéctico, basado en las siguientes categorías: historia, contradicción y trabajo. Con eso, se obtuvo como resultado que se modificaron las diferentes formas de construcción; tanto el método de trabajo como sus configuraciones arquitectónicas. Además, se ha logrado que parte de la memoria haya sufrido modificaciones, implicadas por la burguesía, el capital y el estado, pero que se quede en partes dada la oralidad y la dimensión territorial.

Palabras claves: arquitectura quilombola; patrimonio cultural; memoria quilombola; Afrobrasileña.

\section{Abstract}

\footnotetext{
${ }^{1}$ Bacharelando em Arquitetura e Urbanismo; Universidade Federal de Juiz de Fora; Juiz de Fora, Minas Gerais, Brasil; luis.prado@ arquitetura.ufjf.br.

2 Bacharelanda em Arquitetura e Urbanismo; Universidade Federal de Juiz de Fora; Juiz de Fora, Minas Gerais, Brasil; dayane.maximo@arquitetura.ufjf.br.

3 Professor Associado; Universidade Federal de Juiz de Fora; Juiz de Fora, Minas Gerais, Brasil; leo.ufjf@gmail.com.
} 
The memory and history are the components that spread the identity to the individual, but are governed by interferences and transformations. In this sense, this article's main objective is to critically analyze how the quilombola architecture and cultural heritage has survived. Thus, methodologically, an analysis was made, using dialectical historical materialism, based on the following categories: history, contradiction and work. As a result, it was obtained as a result that the different ways of building were modified; both the working method and its architectural configurations. In addition, it has been achieved that part of the memory has undergone modifications, implied by the bourgeoisie, capital and the state, but remains in parts given the orality and the territorial dimension.

Keywords: quilombola architecture; culture heritage; quilombola memory; afro-brazilian.

\section{Introdução}

Inicialmente, faz-se uma observação aos diversos fatores imersos dentro da produção historiográfica, em que Waisman (2013) vai destacar que a história é uma sucessão de juízos e está acometida aos interesses do presente, sendo continuamente reescrita e dedicada à ideologia também do momento. Consoante a este fator, faz-se um destaque às compreensões de Pollak (1989, p.4) cujo pensamento destaca que "numa perspectiva construtivista, não se trata mais de lidar com os fatos sociais como coisas, mas de analisar como os fatos sociais se tornam coisas. Como e por quem eles são solidificados e dotados de duração e estabilidade" relatando que a história em seu processo construtivo tem sido escrita pelos vencedores. Mostrando uma grande barreira dentro do processo construtivo da história, e colocando-a em um papel ineficaz na sua produção, principalmente de povos marginalizados.

Com isso, pontua-se que a memória se configura como principal perpetuador e de permanência do conhecimento desses povos aqui citados. Isso, para Pollak (1992) pode acabar levando as construções memoriográficas pelo tempo de forma herdada.

A memória, que se torna um tema bastante explorado nos estudos acadêmicos a partir da segunda metade do século XX, é utilizada nessa época, principalmente, como um meio de manutenção do imaginário colonialista e racista, e com uma intensa produção de apagamentos e silenciamentos de heranças negras africanas a partir do movimento transatlântico (CUNHA PAZ, 2019, p. 23), através de sucessivas violências simbólicas, como a árvore do esquecimento (MOREIRA; PERETI, 2019).

Neste lugar se encontrava a árvore do esquecimento. Os escravos homens deviam dar nove voltas em torno dela. As mulheres, sete. Depois disso supunha-se que os escravos perdiam a memória e esqueciam seu passado, suas origens e sua identidade cultural, para se tornarem seres sem nenhuma vontade de reagir ou se rebelar. (ATLÂNTICO NEGRO, 1998, 15min54s) 
Ao se tratar desse movimento, é de exímia importância nos desprendermos da ideia que temos acerca de África e do negro africano, partindo dos conceitos de Mbembe (2001), de que estes se compreendem em conceitos ocidentais, que estruturalmente designa os corpos pretos a um local estereotipado que nega a sua existência.

Também é importante que entendamos que a memória do povo afrobrasileiro parte da ideia da ressignificação. Ressignificação da dor, ressignificação da colonização, do modo de vida e da memória. Memória esta que é trazida por alguns autores da filosofia, como Pessanha, Paz e Saraiva (2019), a partir do conceito de MemORÍa, que seria a memória afrodescendente ligada ao elo mais profundo das ancestralidades africanas, que seria o Orí (palavra de origem iorubá que em português está relacionada a cabeça). Esta MemORÍa seria então a orientação, a possibilidade de se reconstruir enquanto afrodiaspóricos, retomando as origens, e levando em consideração a travessia/o movimento transatlântico, como ponto de partida, rompendo com o mito do negro-africano amnésico/sem memória criado pelo ocidente, para uma reconstrução do indivíduo africano e seus descendentes negros na diáspora aos próprios negros (PESSANHA; PAZ; SARAIVA, 2019), assim como traz a historiadora, professora, roteirista, poeta, intelectual e ativista Beatriz Nascimento em grande parte de sua obra, mas mais especificamente no filme Orí (1989).

A partir disso é possível que se compreenda o corpo negro como corpo-território, uma territorialidade em constante movimento, que herda toda uma bagagem sociocultural das sociedades africanas e das próprias produções a partir da diáspora (CUNHA PAZ, 2019).

O corpo, ao mesmo tempo, significa e é significado, interpreta e é interpretado, representa e é representado. O corpo é, ao mesmo tempo, índice, ícone e símbolo. Daí que o corpo não é apenas um organismo biológico, mas um tecido cultural (OLIVEIRA, 2003 p. 111)

Desta forma, nosso trabalho parte da ideia de que a memória se configura como principal perpetuador da sobrevivência da arquitetura e do patrimônio cultural quilombola ${ }^{4}$ afro-brasileiro. Tendo como principal objetivo, analisar de forma crítica de que modo a arquitetura e o patrimônio cultural quilombola tem sobrevivido, frente às diversas interferências condicionadas historicamente na memória.

\section{Método de análise}

\footnotetext{
4 Vale ressaltar que entende-se as novas significações de quilombo na atualidade, no entanto os quilombos aqui tratados serão os quilombos que de acordo com SILVA (2005), são as "terras de pretos" lugares de sobrevivência dos remanescentes dos cativos.
} 
Metodologicamente, a pesquisa teve caráter básico e qualitativo, foi pautada a partir do método aplicado por Prado e Carneiro (2020), em uma análise interpretativa dos processos consistentes dentro da memória de povos marginalizados. Com isso, no propósito de investigar as relações materiais de produção exteriorizadas pela urgência em existir, fez-se uma análise utilizando o materialismo histórico dialético (NETTO, 2011) fazendo o uso das categorias: (1) história, (2) contradição e (3) trabalho. Por este viés, em uma "pesquisa bibliográfica, a análise buscará identificar a presença e a relação das categorias supracitadas a partir do objeto e dos objetivos da pesquisa" (PRADO; CARNEIRO 2020, p.116).

\section{Resultados}

\subsection{A causa das interferências}

Os espaços e a conformação das cidades têm se construído de forma dialética desde muito tempo, influenciadas, exatamente, pelo capital, burguesia e o Estado. Harvey (2009) vai destacar que os recursos globalizantes têm sido construídos desde 1492, ou até mesmo anteriormente e que a burguesia tanto cria como destrói os fundamentos geográficos: entre eles os fundamentos ecológicos, espaciais e culturais, a partir de suas próprias atividades, construindo um mundo à sua própria imagem e semelhança.

Para além desse fator, Harvey (2018, p.139) vai sublinhar que "o capital se esforça para produzir uma paisagem geográfica favorável a sua própria reprodução e subsequente evolução" e acrescenta que "o modo como a paisagem evolui afeta tanto a acumulação de capital quanto a maneira como se manifestam as contradições do capital e do capitalismo no espaço, no lugar e no tempo". O que rebate diretamente nas contínuas transformações dentro de comunidades quilombolas, que acabam reféns deste sistema.

\subsection{Entre memORÍas}


Em um sistema capitalista, que desde a diáspora africana tenta sistematicamente forjar um apagamento cultural desses povos, construindo uma nação fundada sob tal preceito, ao mesmo tempo em que se nega a relação com ele (MOREIRA; PERETI, 2019), tornando a discussão acerca das políticas do esquecimento tão importantes quanto as políticas da memória (MOREIRA; PERETI, 2019).

Todos sabemos que o estupro foi brutal e implacável. A primeira medida do escravagista direto ou indireto era produzir o esquecimento do negro, esquecimento de seus lares, de sua terra, de seus deuses, de sua cultura, para transformá-lo em vil objeto de exploração. Esse estupro cultural teve transformação para sempre apresentar-se mascarado. O negro, esquecido na sua condição propriamente humana, era objeto de estudo da Antropologia no sentido de medir as dimensões de sua cabeça, de sua condição fálica, de seus instintos, de seu comportamento reflexo. Ao estupro do esquecimento, dirigido às origens, sucedeu a chamada aculturação, outra forma sinistra de cortar os laços religiosos e culturais com as mesmas origens. (NASCIMENTO, 1997, p. 159-160)

A árvore do esquecimento, forte símbolo de um processo de apagamento constante das práticas e memórias culturais afrodescendentes foi simbolicamente transportada junto ao movimento transatlântico (MOREIRA; PERETI, 2019), sendo fixada e multiplicada de forma rápida e severa, perpetuando de forma intensa até os dias atuais, com um carácter ontológico e epistemológico (CUNHA PAZ, 2019), que variam entre desarranjo de memórias, à traumas físicos e simbólicos, dentre outras. Essa manobra secular empenhada em sepultar lembranças (CUNHA PAZ, 2019), ou seja, produzir apagamentos, silenciamentos e morte da memória, é trazida pela professora Giselle Beiguelman (2019) como “memoricídios". Estes que sempre estiveram longe de serem ocasionais, onde Cunha Paz (2019, p.156) traz a partir de Fanon (2008) que "o negro precisava ser mantido dentro de um isolamento cultural e ontológico, onde só restaria a ele o mundo do branco, as experiências do "eu-universal branco", ou do "eu-negro" gestado pelo racismo".

Com isso, dentre os processos de supressão, que agem de forma racista ao povo negro, advindos dos recursos globalizantes e do capital, da burguesia e do estado, Gonzales e Hasenbalg (1982, p.97) vai destacar que a população negra brasileira vai se encontrar em constante desvantagem, dentro da qual "o negro enfrenta uma estrutura de oportunidades sociais diferente e mais desfavorável que a do branco".

Nesta perspectiva, esses povos submetidos às constantes disputas por terra, processos de alienação do povo e criação do contexto de civilidade imerso nos recursos de urbanização, 
se não tiverem ligações emergentes compostas em uma memória suprimida, vão acabar sofrendo enquanto povo nesse ambiente urbano, como destaca Krenak (2019, p.9)

A modernização jogou essa gente do campo e da floresta para viver em favelas e em periferias, para virar mão de obra em centros urbanos. Essas pessoas foram arrancadas de seus coletivos, de seus lugares de origem, e jogadas nesse liquidificador chamado humanidade. Se as pessoas não tiverem vínculos profundos com sua memória ancestral, com as referências que dão sustentação a uma identidade, vão ficar loucas neste mundo maluco que compartilhamos.

Por este viés, se retoma aos sistemas da memória suprimida levantada por Prado e Carneiro (2020, p.117, itálico dos autores) ao citar a partir de Pollak que grupos sociais submetidos a constante violência e métodos de desvalorização "ainda sim conseguem manter em sua memória aspectos ocorridos historicamente pela memória subterrânea, e que esta memória tende a retornar posteriormente", tendo assim a possibilidade de manutenção cultural, mas está acometida a transformações que podem agir de forma grave. Pontua-se assim a oralidade como forma mantenedora desta memória.

\subsection{No interior das memORÍas e interferências: as passagens para a sobrevivência}

A trajetória da luta das comunidades quilombolas "vem de longa data, desde quando os nossos antepassados pisaram neste solo chamado Brasil" (SILVA, 2013, p.153) onde suas passagens para a sobrevivência foram caucadas de estigmas da violência, motivados pelo capitalismo, gerando atrocidades contra a humanidade. Para Silva (2013, p.154)

A população negra oriunda do continente africano para o Brasil teve, por consequência, todo o seu desenvolvimento social desestruturado pelo sistema escravagista que serviu a interesses do capitalismo comercial, enfrentando o sistema com estratégias de agrupamentos, os chamados quilombos, signos de espaço tanto de resistência à opressão da escravidão quanto de espaço de construção de laços sociais identitários. Nesses antigos espaços, encontram-se populações descendentes do povo negro, as denominadas populações quilombolas. Elas possuem uma relação com a terra que ultrapassa a mera questão produtiva. A terra é sua identidade, e está intimamente ligada com seu modo de ser e se perceber no mundo, pois dela desdobram-se relações sociais, econômicas e culturais próprias (bens materiais e imateriais).

Partindo para a terra de uso de refúgio, temos a ideia de quilombo como territóriomemória, como uma forma de resistência e sobrevivência, por ser um espaço de trocas e 
compartilhamento de conteúdos simbólico-afetivos, e por se dar em relação a um contexto social, cultural e político específico que enfatiza as particularidades dos sujeitos que a constituem (ROCHA, 2010) formando um território de salvaguarda do patrimônio. Porém, perante um o estigma de invisibilidade calcado em um passado de fugas, onde era necessário se esconder, ou seja, se ressignificar para continuar existindo diante do sistema colonialista opressor, as comunidades quilombolas acabaram por adotar sistemas sociais e parâmetros de sociabilidade e territorialidade que fizeram com que muitos dos conteúdos ancestrais acabassem se dissolvendo com o tempo em função de diversas interferências, desde as identitárias, partindo de que a identidade desse grupo se define pelo imaginário social construído a partir das suas vivências, às monetárias (Furtado, Sucupira e Alves 2014), regidas pelo Capital, pela Burguesia e pelo Estado.

Este sistema de interferências é causado principalmente nos recursos de apropriação da terra, em primazia devido às circunstâncias vividas entre mais de 300 anos de escravidão, e já no pós-abolição, por eventos históricos foi impedido o apoderamento das terras pela população negra onde a burguesia temia essa posse (SILVA, 2013). Em 1850 houve a Lei de Terras em uma política de privilégio da burguesia que segundo Silva (2013, p.154)

Ao longo dos anos, essa política sofreu algumas alterações sem grande relevância, pois o ordenamento jurídico ainda se manteve a favor das elites, somado à sucessão de governos autoritários, no contexto brasileiro. Para essas elites, a ocupação, a compra, a venda e a herança vieram a se constituir direitos garantidos pelo Estado com o tempo, relegando a população negra à opressão, à exploração e à humilhação, acarretando desamparo social e jurídico.

Com isso, a partir desses métodos de supremacia Silva (2013, p.154-155) vai destacar que

mesmo com o fim da escravidão, as comunidades quilombolas - as que resistiram às tentativas de represálias de fazendeiros - continuaram a existir. Isso se deveu tanto pela força dos seus líderes negros, quanto pelo fato de muitos dos negros libertos não possuírem alternativas para conseguir condições dignas de vida, devido à ausência de recursos financeiros e de assistência e incentivo do Estado. Por essa razão particular, houve a formação de novas comunidades quilombolas após a escravidão. Dado o ranço escravocrata da sociedade brasileira, os quilombos não ficaram imunes à violência, e muitos foram alvo de grilagens de latifundiários. 
Mostrando-se, assim, anos de procedimentos de enviesamento do acesso a terra, que mesmo durante o começo século XX em um discurso de igualdade na inserção do povo não branco, na perspectiva cultural e simbólica, ainda assim o direito a terra enquanto propriedade quilombola se perdurou sendo invisibilizada (SILVA, 2013). A verdadeira conquista segundo Silva (2013, p. 156)

(...) ocorreu com a promulgação da CF de 1988, que no seu Artigo 68, caput, do Ato das Disposições Constitucionais Transitórias (ADCT), estabeleceu: "Aos remanescentes das comunidades dos quilombos que estejam ocupando suas terras é reconhecida a propriedade definitiva, devendo o Estado emitirlhes os títulos respectivos". Outra importante conquista foi a criação da Fundação Cultural Palmares (FCP), em 1988.

No entanto, embora haja a conquista judiciária, a população quilombola não se tornou desprendida das interferências globalizantes e principalmente as expressas pela burguesia, pelo capitalismo e pelo estado. Tendo inclusive uma das grandes interferências propiciadas pelo grande desenvolvimento das cidades, causando um desprendimento de remanescentes de quilombos, trazidos para a cidade devido a necessidade de subsistência, concebendo a formação do quilombo urbano, que embora haja a perda patrimonial material, estes espaços, se tornam locais de manutenção do patrimônio imaterial, advindas pelas expressões culturais e religiosas (SILVA,2005).

\subsection{A sobrevivência da arquitetura enquanto patrimônio cultural (material e imaterial): uma visita a Colônia do Paiol}

Observando entre as comunidades rurais remanescentes na história, pela ótica das transformações arquitetônicas, Farias (1951) vai destacar que as arquiteturas quadrangulares vernaculares, com técnicas em terra e madeira, representadas no Brasil, tem referências provindas de povos bantu ocidentais, e por alguns grupos sudaneses do golfo de Guiné. Mas foram realizadas apropriações relativas à geografia dadas as condições brasileiras, entre elas: o clima, topografia e as circunstâncias de fuga. Mostrando assim, referencial cultural africano e a criação de uma cultura própria brasileira.

Entre seus processos construtivos, Farias (1951) também relata que algumas técnicas foram de influência europeia, mostrando assim uma interferência externa. Mas, percebe-se também que, entre seus movimentos históricos até se colocarem nos dias atuais, a arquitetura 
quilombola foi frequentemente modificada pelas condições sublinhadas por Harvey (2009, 2018), dispostas pelo Capital e pela Burguesia. Transformando assim sua forma, os meios de produção e o trabalho. Configurando mudanças significativas no patrimônio material e imaterial.

Com isso, entre as diversas trajetórias de interferências e metodologias de sobrevivência, realiza-se uma análise pautada na colônia do Paiol. Observando as existências espaciais e do patrimônio cultural. A Colônia do Paiol, segundo Silva (2005), se insere no contexto das comunidades quilombolas em Minas Gerais, particularmente na Zona da Mata. A comunidade está localizada no município de Bias Fortes/MG, com população aproximada de 600 moradores. Na origem desta ocupação quilombola, se dá ao ano de 1891, com a doação de terras a nove ex-escravos, e atualmente, os descendentes destes herdeiros permanecem na Colônia.

Dentre as mudanças apresenta-se um fator inicial por causa da interferência. A comunidade se localiza de forma bem próxima a cidade de Bias fortes, trazendo interferências causadas pelo povo que habita essa cidade vizinha. Um fator importante apresentado por Silva (2005) são os processos de invasão de terras, onde parte das terras concedidas pela comunidade foi invadida, em um propósito capitalista. Outro destaque apresentado por Silva (2005) é a inserção desses povos no mercado de trabalho local, impostas pelo sistema, onde parte teve que sair também da colônia, que podem ser causados pela não soberania alimentar. Esses povos assim imersos dentro da bolha capitalista e as imposições causadas pela burguesia e o capital, como destacado em Harvey $(2009,2018)$, acaba por transformar de forma expressiva a arquitetura e o patrimônio imaterial quilombola dessa região.

Dentre as transformações observadas durante a visita a comunidade, notamos a permanência de técnicas, mesmo que com materiais novos. Sendo um deles que nomeamos como "novo adobe", onde com o tijolo cerâmico se construiu as casas, mas apegados às técnicas construtivas ancestrais, como a aplicação de terra. Outro fator de permanência é a morfologia de instalação arquitetônica, que se configura em barrancos, com quintais, e janelas com visão para as casas vizinhas e a estrada de acesso. O que demonstra uma permanência em uma memória coletiva, propiciadas pela oralidade, meio bastante enfatizado por Silva (2005) quanto principal assegurador cultural nesta comunidade.

\section{Considerações finais}


Por fim, os principais resultados obtidos, detalham que as trajetórias do cotidiano histórico quilombola foi marcado por diversas interferências, que vão agir de forma pontual na destruição e transformação do patrimônio cultural quilombola. Entre essas interferências, inicialmente observa-se o viés capitalista opressor, que atuou de forma escravagista e violenta, em uma característica de opressão. Além disso, observamos que a terra atua enquanto importante assegurador patrimonial enquanto território-memória. Território, que enfrentou grandes estigmas, para conseguir sua asseguração, mas enfrenta cotidianamente invasões de viés capitalista.

Com isso, dadas essas diversas interferências a memória se configura como principal mantenedora do patrimônio imaterial e consequentemente o patrimônio material , onde a oralidade se situa em um fator principal, dotando a cultura e a arquitetura dotada de duração e algumas estabilidades.

\section{Referências}

ATLÂNTICO NEGRO, NA ROTA DOS ORIXÁS. Direção: Renato Barbieri. Produção: Renato Barbieri. Roteiro: Victor Leonardi e Renato Barbieri. Fotografia de Carlos André Zalasik. Brasil: GAYA Filmes, 1998. Disponível em:

<http://www.gayafilmes.com/filme/atlantico-negro-na-rota-dos-orixas/.> Acesso em: 10 nov. 2020 .

CUNHA PAZ, F. P. Memória, a Flecha que Rasura o Tempo: Reflexões Contracoloniais Desde uma Filosofia Africana e a Recuperação das Memórias Usurpadas Pelo Colonialismo. PROBLEMATA: International Journal of Philosophy, [s. 1.], v. 10, ed. 2 (2019), p. 147-166, 2019. Disponível em:

<https://periodicos.ufpb.br/ojs/index.php/problemata/article/view/49127>. Acesso em: 10 nov. 2020.

CUNHA PAZ, F. P. Na casa de Ajalá: comunidades negras, patrimônio e memória contracolonial no Cais do Valongo - a "Pequena África". Dissertação de Mestrado apresentada no Programa de Pós-Graduaçao em Desenvolvimento, Sociedade e Cooperação Internacional - UnB, 2019.

FANON, F. Pele Negra, Máscaras Brancas. Tradução de Renato de Silveira. Salvador: EDUFBA, 2008.

FARIA, C. Origens culturais da habitação popular no Brasil. Boletim do Museu Nacional. Rio de Janeiro: Secção de Antropologia, n. 12, 1951.

FURTADO, M. B. SUCUPIRA, R. L. ALVES , C. B. . Cultura, identidade e subjetividade quilombola: uma leitura a partir da psicologia cultural. Psicologia \& Sociedade, v.26(1), p. 106-115 . 2014.

HARVEY, D. 17 contradições e o fim do capitalismo. São Paulo: Boitempo, 2018. 
.Espaços de Esperança. 3. edição. São Paulo: Edições Loyola, 2009.

KRENAK. Ailton. Idéias para adiar o fim do mundo. São Paulo: Schwarcz, 2019.

MBEMBE, A. As Formas Africanas de Auto-Inscrição. Estudos Afro-Asiáticos, ano 23, nº 1, p. 171-209, 2001.

MOREIRA, R. B.; PERETI, E. A ÁRVORE DO ESQUECIMENTO E AS TENTATIVAS DE DESTRUIÇÃO DA MEMÓRIA AFRODIASPÓRICA. Revista UNIABEU, [s. 1.], v. 13, n. Número especial, ed. 33, p. 284-197, jan/jun 2020.

NASCIMENTO, A. do. Toth I - Pensamento dos Povos Africanos e Afrodescendentes. Brasília: Secretaria Especial de Editoração e Publicações, 1997.

PESSANHA, E. A. de M.; PAZ, F. P. C.; SARAIVA, L. A. F. Na travessia o negro se desfaz: vida, morte e memÓRÍa, possíveis leituras a partir de uma filosofia africana e afrodiaspórica. Revista Internacional de Filosofia: Dossiê Interfaces da Filosofia Africana, Santa Maria, v. 10, p. 110 -127, 10 set. 2019. Disponível em:

<https://periodicos.ufsm.br/voluntas/article/view/39949>. Acesso em: 10 nov. 2020.

OLIVEIRA, E. O. Cosmovisão Africana no Brasil: elementos para uma filosofia afrodescendente. Fortaleza: LCR, 2003

POLLAK, M. Memória e identidade social. Revista Estudos Históricos, Rio de Janeiro, v. 5, n. 10, p. 200-215, jul. 1992. ISSN 2178-1494.

Memória, esquecimento, silêncio. Revista Estudos Históricos, Rio de

Janeiro, v. 2, n. 3, p. 3-15, jun. 1989. ISSN 2178-1494.

PORTO, W. Da escravidão à ditadura, esquecimento é marca do Brasil, diz professora. Giselle Beiguelman discute no podcast a relação turbulenta do país com sua própria memória. Folha de São Paulo, [S. 1.], 10 ago. 2019. Disponível em:

$<$ https://www1.folha.uol.com.br/ilustrissima/2019/08/da-escravidao-a-ditadura-esquecimentoe-marca-do-brasil-diz-professora.shtml>. Acesso em: 10 nov. 2020.

PRADO, L. O. C.; CARNEIRO, L. de O. Entre memórias e interferências: a sobrevivência da arquitetura e do patrimônio cultural indígena. Revista Científica ANAP Brasil, [S.1.], v. 13, n. 30, dez. 2020. ISSN 1984-3240. Disponível em:

<https://www.amigosdanatureza.org.br/publicacoes/index.php/anap_brasil/article/view/2609/ 2385>. Acesso em: 13 Dez. 2020.

ROCHA, G. de F. F. A territorialidade quilombola ressignificando o território brasileiro: uma análise interdisciplinar. E-cadernos CES: Identidades, cidadanias e Estado, [s. 1.], 2010. Disponível em: 〈https://journals.openedition.org/eces/417〉. Acesso em: 27 set. 2020.

SILVA, D. A. O PASSEIO DOS QUILOMBOLAS E A FORMAÇÃO DO QUILOMBO URBANO. 2005. p. 432. Tese de doutorado (Doutorado) - Pontifícia Universidade Católica De São Paulo, São Paulo, março de 2005. 
SILVA, I. F. ACESSO A TERRA “CAMINHO DE MUITAS CURVAS”: DEPOIMENTO DE UM QUILOMBOLA. In: SILVA, Tatiana Dias Silva; GOES, Fernanda Lira, (Org.). Igualdade racial no Brasil: reflexões no Ano Internacional dos Afrodescendentes. Brasília: Ipea, 2013. p. 137-152. Disponível em:

<http://www.ipea.gov.br/igualdaderacial/images/stories/pdf/livro_igualdade_racialbrasil01.pd f> Acesso em 10 dez. 2020

WAISMAN, M. O interior da história: historiografia arquitetônica para uso de latinoamericanos. São Paulo: Perspectiva, 2013. 